\title{
PROPERTIES OF FUNCTIONS RELATED TO HADAMARD TYPE INEQUALITY AND APPLICATIONS
}

\author{
WEN WANG AND XINQUAN ZHANG
}

Abstract. The aim of this paper is first to generalize Hadamard's inequality. Further, Schur $m$ power convex of the associated continuous function of two variables by utilize the Hadamard type inequalities are obtained. As applications, a inequality related special mean is established. And we also improve Jordan's inequality.

Mathematics subject classification (2010): 26D15, 26D10.

Keywords and phrases: Hadamard's inequality, Jordan's inequality, Schur m-power convexity, Schur convexity, mean.

\section{REFERENCES}

[1] Y. Chu, G. Wang And X. Zhang, Schur convexity and hadamard's inequality, Math. Ineq. Appl., Preprint.

[2] Y. M. ChU, T. C. Sun, The Schur harmonic convexity for a class of symmetric functions, Acta mathematica Scientia, (2010), 30B(5):1501-1506.

[3] V. ČUlJAK, A remark on Schur-convexity of the mean of a convex function, J. Math. Ineqal., 9(4)(2015), 1133-1142.

[4] S. S. Dragomir, C. E. M. Pearce, Selected Topics on Hermite-Hadamard Inequalities and Applications, RGMIA Monographs, Victoria University, 2000.

[5] S. S. Dragomir, Two functions in connection to Hadamard's inequalities, J. Math. Anal. Appl., 167 (1992), 49-56.

[6] S. S. Dragomir, Further properties of some mappings associated with Hermite-Hadamard's inequalities, Tamkang. J. Math., 34(1)(2003), 45-57.

[7] N. Elezović And J. PEČARIĆ, A note on Schur-convex fuctions, Rocky Mountain J. Math. 2000,30 (3): 853-856.

[8] K. Z. GUAN, Ruke GuAn, Some properties of a generalized Hamy symmetric function and its applications, J.Math. Analysis Appl., 376 (2011), 494505.

[9] R. KlÉn, M. Visuri And M. VuORInen, On Jordan type inequalities for hyperbolic functions, J. Inequal. Appl. 2010 (2010), Art. ID 362548, 14 pages, doi:10.1155/2010/362548.

[10] R. B. Manfrino, R. V. Delgado, J. A. G. Ortega, Inequalities a Mathematical Olympiad Approach, Birkhäuser, 2009.

[11] A. W. Marshall, I. Olkin, B. C. Arnold, Inequalities: theory of majorization and its application (Second Edition), New York: Springer Press, 2011.

[12] M. MERKLE, Conditions for convexity of a derivative and some applications to the Gamma function, Aequ. Math., 55 (1998), 273-280.

[13] M. MERKLE, Representation of the error terms in Jensen's and some related inequalities with applications, J. Math. Analysis Appl., 231 (1999), 76-90.

[14] D. S. Mitrinović, J. E. PeČArić, A. M. Fink, Classical and New Inequalities in Analysis, Kluwer Academic Publishers, Dordrecht.

[15] C. P. Niculescu, The Hermite-Hadamard inequality for log-convex functions, Nonlinear Analysis, 75 (2012), 662-669.

[16] M. E. ÖZDEMIR, A theorem on mappings with bounded derivatives with applications to quadrature rules and means, Appl. Math. Lett. 13 (2000), 19-25. 
[17] J. E. Pečarić, F. Proschan, Y. L. Tong, Convex Functions, Partial Orderings and Statistical Applications, Academic Press, 1991.

[18] F. QI, D. W. NiU AND B. N. GUO, Refinements, generalizations, and applications of Jordan's inequality and related problems, J. Inequal. Appl., 2009 (2009), Art. ID 271923, 52 pages.

[19] H. N. SHI, Schur-convex functions related to Hadamard-type inequalities, J. Math. Inequal., 1, 1, (2007): 127-136.

[20] W. T. Sulaiman, Schur Convexity and Hadamard's Inequality, Global Journal of Sci. frontier Research, (2011), 11, 1.

[21] K. L. Tseng, Shiow-Ru Hwang, S. S. Dragomirc, New Hermite-Hadamard-type inequalities for convex functions (I), Appl. Math. Lett., 25 (2012), 1005-1009.

[22] W. WANG, S. G. YANG, Schur m-power convexity of generalized Hamy symmetric function, J. Math. Inequal., 2014, 8(3): 661-667.

[23] W. WANG, S. G. YANG, Schur m-power convexity of a class of multiplicatively convex functions and applications, Abstract and Applied Analysis, 2014, Article ID 258108, 12 pages,http://dx.doi.org/10.1155/2014/258108

[24] Sh.-H. Wu And L. Debnath, A new generalized and sharp version of Jordan's inequality and its applications to the improvement of the Yang Le inequality, Appl. Math. Letters, 19 (12) (2006), 13781384.

[25] Y. WU, F. QI, Schur harmonic convexity for difference of some means, Analysis, (2012), 32:263-270.

[26] ZH-H. YANG, Schur power comvexity of the Stolarsky means, Publ. Math. Debrecen, 80, 1-2 (2012), 43-66 DOI: 10.5486/PMD.2012.4812.

[27] ZH-H. YANG, Schur power convexity of Gini means, Bull. Korean Math. Soc., 50, 2 (2013), 485-498.

[28] ZH-H. YANG, Schur power comvexity of the daróczy means, Math. Inequal. Appl., 16, 3 (2013), $751-762$.

[29] ZH-H. YANG, New sharp Jordan type inequalities and their applications, http://arxiv.org/abs/1206.5502v1

[30] X. M. Zhang, Geometrically-Convex Functions, Anhui Univ. Press, Hefei, 2004 (in Chinese) 